\title{
PENGARUH ORIENTASI PELANGGAN, ORIENTASI PEMBELAJARAN DAN MOTIVASI INTRINSIK TERHADAP PENJUALAN ADAPTIF \\ (Studi kasus PT. Oriflame Yogyakarta)
}

\author{
Putri Wulandari \\ andari83@yahoo.co.id
}

\begin{abstract}
ABSTRAK
Tujuan dari penelitian ini adalah : (1) Untuk mengetahui Pengaruh Orientasi Pelanggan terhadap Penjualan Adaptif PT. Oriflame Cabang Yogyakarta. (2) Untuk mengetahui Pengaruh Orientasi Pembelajaran terhadap Penjualan Adaptif PT. Oriflame Cabang Yogyakarta. (3) Untuk mengetahui Pengaruh Motivasi Intrinsik terhadap Penjualan Adaptif PT. Oriflame Cabang Yogyakarta.

Teknik pengambilan sampel yang digunakan adalah metode sensus. Sampel dalam penelitian ini berjumlah 50 respoden, dimana respondennya adalah tenaga penjual PT. Oriflame cabang Yogyakarta.Analisis data menggunakan analisis regresi berganda, uji $\mathrm{F}$ dan uji $\mathrm{t}$ dengan menggunakan progam komputer SPSS versi 16.0. Hasil analisis menunjukkan bahwa kualitas kinerja Oriflame yang diukur dengan variabel-variabel Oreintasi Pelanggan (X1), Orientasi Pembelajaran (X2) dan Motivasi intrinsik (X3) tidak berpengaruh signifikan terhadap penjualan adaptif, diperoleh persamaan regresi sebagai berikut : $\mathrm{Y}=0,284 \mathrm{X} 1+0,187 \mathrm{X} 2+0,052 \mathrm{X} 3$, besarnya pengaruh secara bersama-sama dapat diketahui dari $\mathrm{F}$ hitung sebesar 2.600 dan nilai koefisien determinasinya $\left(\mathrm{R}^{2}\right)$ sebesar 0,089, artinya variabel-variabel Orientasi Pelanggan (X1), Orientasi Pembelajaran (X2) dan Motivasi Intrinsik (X3) secara bersama-sama tidak berpengaruh terhadap penjualan adaptif sebesar 8,9\% dan 91,1\% dipengaruhi oleh variabel lain. Besarnya pengaruh secara individual dapat diketahui dengan uji t menunjukkan signifikasi faktor-faktor kualitas kinerja yang berpengaruh positif terhadap penjualan adaptif yaitu variabel orientasi pelanggan (X1) 0,048, Orientasi Pembelajaran (X2) 0,191, dan Motivasi intrinsik (X3) 0,709.
\end{abstract}

Kata kunci : Orientasi pelanggan, Orientasi pembelajaran, Motivasi intrinsik, Penjualan adaptif

\section{PENDAHULUAN}

1.1 Latar Belakang

Ketatnya persaingan

antarperusahaan dalam era ekonomi global menuntut perusahaan untuk selalu menjadi yang terdepan dan terbaik dalam memberikan pelayanan yang memuaskan kepada konsumen. Persaingan yang terjadi mengharuskan setiap perusahaan untuk bersikap adaptif kepada konsumen. Karena dengan adanya persaingan tersebut justru merupakan salah satu unsur penting dalam menyusun strategi pemasaran yang tepat. Strategi pemasaran yang tepat dapat memberikan keuntungan positif bagi perusahaan dalam meningkatkan volume penjualan dan pangsa pasar demi memenangkan pasar persaingan. Kondisi ini menuntut perusahaan untuk menjadi yang terdepan, tercepat dan terbaik dalam memberikan pelayananya kepada konsmen. Satu hal yang dapat diupayakan agar memenangkan persaingan adalah dengan mengelola tenaga penjual. Pengelolaan tenaga penjual secara profesional membuka peluang bagi perusahaan untuk memenangkan persaingan yang 
berkelanjutan. Disamping itu perusahaan juga akan memenangkan persaingan apabila berorientasi kepada pelanggan melalui tenaga penjualannya.

Knight et al. (2007) berpendapat bahwa orientasi pelanggan merupakan kunci sukses baik tenaga penjual dan organisasi di masa datang. Perusahaan dan tenaga penjualnya harus makin fokus pada apa yang menjadi harapan dan kebutuhan pelanggan. Tugas mengelola hubungan dengan pelanggan bukanlah tugas mudah. Seorang tenaga penjual tidak hanya dituntut melayani pelanggan dengan baik saja, tetapi juga dituntut untuk dapat mencapai target penjualan, target pelanggan dan target keuntungan yang telah ditetapkan oleh perusahaan melalui manajer penjualan. Lebih jauh, praktek penjualan yang berorientasi pelanggan mampu meningkatkan hubungan penjualpembeli (William, 1998).

Untuk dapat terus mengembangkan kemampuan dalam persaingan usaha, dibutuhkan suatu tambahan pengetahuan dan kemampuan untuk menyerap pengetahuan tersebut agar dapat diterapkan dalam pekerjaan. Pembelajaran adalah pengembangan dari pengetahuan baru atau kemampuan yang mempunyai potensi untuk mempengaruhi perilaku (Slater dan Narver, 1995). Dengan memiliki orientasi pembelajaran yang kuat maka seseorang akan terus berusaha meningkatkan kemampuan yang dimilikinya untuk menunjang pekerjaannya dan memberikan hasil terbaik dari pekerjaannya. Hal inipun diharapkan dari para tenaga penjual yang ada apabila terus menerus belajar untuk mengembangkan kemampuan maka mereka akan dapat menjadi semakin terampil dan dapat meningkatkan kinerjanya.

Orientasi

pembelajaran

dipandang sebagai Investasi jangka panjang dari pada pengeluaran jangka panjang perusahaan. Banyak dari manajer lebih memfokuskan pada kinerja jangka pendek dan mengharapkan tenaga penjual untuk bekerja lebih keras yang dapat memberikan motivasi atau meningkatkan keahlian tenaga penjual yang bermanfaat untuk kinerja tenaga penjual dalam jangka panjang. Orientasi pembelajaran mendorong tenaga penjual untuk meningkatkan kemampuannya dalam menjalankan pekerjaannya. Orientasi pembelajaran merupakan pokok dari kepentingan intristik dalam sebuah pekerjaan seperti menghadapi tantangan pekerjaan (Sujan et al. 1994). Tenaga penjual dapat mencapai tujuan akan pembelajaran untuk bekerja lebih baik dan mendemonstrasikan kemampuannya kepada orang lain (Sujan, 1994). Dalam manajemen penjualan, orientasi pembelajaran merupakan salah satu faktor penting yang berperan dalam menghasilkan tenaga penjual yang memiliki kualitas tinggi (Sujan et al. 1994; Ellis dan Raymond, 1993). Adanya orientasi pembelajaran akan membuat tenaga penjual memperoleh pengalaman dan mereka akan lebih mudah menyesuaikan diri terhadap situasi dan kondisi penjualan yang dihadapi termasuk dalam usahanya meningkatkan kinerja. Hasiholan (1994) dalam penelitiannya menunjukkan bahwa orientasi pembelajaran berpengaruh positif terhadap penjualan adaptif.

Selain itu motivasi intrinsik juga sangat berbengaruh terhadap tenaga penjual, motivasi dalam menunjang pemenuhan kebutuhan berprestasi sangat besar, dangan kata lain motivasi mempunyai hubungan yang positif terhadap prestasi kerja yang lebih baik dan sebaliknya. Motivasi tercakup konsep-konsep, seperti kebutuhan berprestasi, kebutuhan berafiliasi, kebiasaan, dan keingintahuan seseorang terhadap sesuatu. Ditinjau dari sumbernya, motivasi terbagi menjadi dua yaitu motivasi intrinsik dan motivasi ektrinsik. Motivasi intrinsik adalah motivasi yang timbulnya tidak 
memerlukan rangsangan dari luar karena memang telah ada dalam individu itu sendiri, yaitu sejalan dengan kebutuhannya. Sedangkan motivasi ektrensik timbul karena adanya rangsangan dari luar individu, misalnya dalam bidang pendidikan terdapat minat yang positif terhadap kegiatan pendidikan timbul karena melihat manfaatnya. Motif intrinsik lebih kuat dari motif ekstrinsik.

Motivasi secara umum didefinisikan sebagai psikologis internal yang merangsang seseorang untuk terlibat dalam prilaku tertentu, individu mempunyai pilihan di antara berbagai alternatif (Brown dan Peterson 1994; Spector 2000). Karena prestasi kerja adalah perilaku manusia, teori motivasi sangat penting untuk pemahamannya.

Selama lebih dari satu abad, psikolog telah mempelajari peran motivasi sebagai energizer perilaku manusia dan telah menemukan bahwa itu adalah suatu faktor penentu kinerja (Spector 2000; Steers dan Porter 1991; Steers, Mowday, dan Shapiro 2004). Di tempat kerja, motivasi sering dipandang sebagai fungsi manajerial kunci dimana karyawan didorong untuk mencapai hasil yang diharapkan dalam pekerjaan mereka dan dengan demikian untuk melayani tujuan organisasi (Ilgen dan Klein 1988; Steers dan Porter1991; Steers, Mowday, dan Shapiro 2004). perilaku kerja dapat dilihat sebagai termotivasi intrinsik maupun ekstrinsik (Chonko, Tanner, dan Weeks 1992; Dubinsky dan Skinner 2002). Motivasi intrinsik terlibat dalam kegiatan untuk kesenangan dan kepuasan yang berasal dari itu, sedangkan ekstrinsik Motivasi terjadi ketika perilaku terlibat sebagai sarana berakhir, bukan untuk kepentingan diri sendiri (Pullins 2001; Valle-rand dan Bissonnette 1992).

$$
\text { Banyak penelitian yang }
$$

dilakukan penjual menunjukkan bahwa motivasi sangat penting bagi keberhasilan organisasi karena efeknya pada tenaga sikap penjual, niat perilaku, dan kinerja (misalnya, Hibah et al. 2001; Pullins 2001). Pernyataan tersebut menunjukkan bahwa motivasi karyawan adalah komponen kunci dari persamaan kinerja dan dengan demikian merupakan aset strategis untuk bersaing (Steers, Mowday, dan Shapiro 2004). Karena pentingnya motivasi, peneliti telah mengusulkan sejumlah teori untuk menjelaskan apa memotivasi manusia yaitu, kebutuhan, penguatan, harapan, teori self-efficacy, ekuitas, dan tujuan baru (Spector 2000).

Spiro dan Weitz (1990:62) mendefinisikan penjualan adaptif (adaptive selling) sebagai suatu aktivitas mengubah perilaku penjualan selama ataupun setelah terjadinya interaksi dengan pelanggan, yang dilakukan berdasarkan pada informasi yang diterima mengenai situasi penjualan. Bagi seorang tenaga penjual, kemampuan penyesuaian diri (adaptive selling) dengan lingkungan dan pelanggan tidak dapat terbentuk dan tertanam dengan sendirinya dalam diri setiap tenaga penjual. Melainkan terbentuk dari sebuah proses belajar yang intens dan terencana dengan baik (Sujan et.al. 1994:39). Penjualan adaptif membutuhkan sebuah perencanaan penjualan yang baik dan kesiapan mental, karena arti penting penjualan adaptif adalah kemampuan tenaga penjual dalam merubah perilaku mereka, sehingga aktivitas penjualan sesuai dengan situasi yang mereka hadapi (Sujan et.al., 1994:40).

1.2 Rumusan Masalah

1.2.1 Bagaimana pengaruh Orientasi Pelanggan terhadap penjualan adaptif?

1.2.2 Bagaimana pengaruh Orientasi Pembelajaran terhadap penjualan adaptif?

1.2.3 Bagaimana pengaruh Motivasi Intrinsik terhadap penjualan adaptif?

1.3 Tujuan Masalah 
Adapun tujuan penelitian ini adalah :
1.3.1 Untuk menganalisis pengaruh faktor orientasi pelanggan terhadap penjulan adaptif.
1.3.2 Untuk menganalisis pengaruh faktor orientasi pembelajaran terhadap penjualan adaptif.
1.3.3 Untuk menganalisis pengaruh faktor motivasi intrinsik terhadap penjualan adaptif

\section{LANDASAN TEORI}

2.1 Tinjauan Pustaka

2.1.1 Definisi Penjualan Adaptif

$$
\text { Konsep penjualan adaptif }
$$
(adaptive selling) merupakan konsep kunci dalam literatur penjualan (Anglin et al 1990:81). Spiro dan Weitz (1990:62) mendefinisikan penjualan adaptif sebagai suatu aktivitas mengubah perilaku penjualan selama ataupun setelah terjadinya interaksi dengan pelanggan, yang dilakukan berdasarkan pada informasi yang diterima mengenai situasi penjualan. Seorang tenaga penjualan dikatakan memiliki tingkat penjualan adaptif yang tinggi apabila dapat menggunakan pendekatan penjualan yang berbeda secara tepat pada saat transaksi dengan pelanggan dan pada saat membuat keputusan selama transaksi penjualan berlangsung untuk situasi penjualan yang berbeda. Sebaliknya tenaga penjual dikatakan memiliki tingkat penjualan adaptif yang rendah apabila mereka hanya menggunakan teknik pendekatan penjualan dan pengambilan keputusan penjualan yang sama untuk seluruh transaksi penjualan yang dilakukannya dalam bentuk situasi penjualan apapun (Farida, 2005:5).

\subsubsection{Orientasi Pelanggan}

\section{Orientasi}

pelanggan didefinisikan sebagai usaha menolong pelanggan untuk membuat keputusan pembelian yang tepat untuk memuaskan kebutuhan pelanggan (Saxe dan Weitz 1982)."Customer orientation:
Effects onCustomer Service Perceptions and Outcome Behavior",manajer harus berusaha untuk mengumpulkan, menganalisa, bertindak, dan menyebarkan informasi tentang kebutuhan serta keinginan pelanggan. Perusahaan yang berorientasi pada pelanggan memiliki produksi dan kinerja karyawan yang lebih baik. Untuk dapat memperoleh keunggulan dalam bersaing, perusahaan harus dapat mengembangkan orientasi pelanggan dengan menciptakan, memperoleh, dan memindahkan pengetahuan dalam mengubah perilaku karyawan untuk meningkatkan kinerja mereka serta memuaskan pelanggan. Karyawan yang berorientasi pada pelanggan merupakan kontributor penting untuk menciptakan hubungan yang positif antara pelanggan dan karyawan, untuk itu perusahaan jasa harus dapat memiliki karyawan garis depan (frontliner) yang memiliki kemampuan, dan termotivasi untuk berorientasi penuh pada pelanggan.

\subsubsection{Orientasi Pembelajaran Sinkulaetal.}

mengkonsepsikanorientasipembelajarans ebagaiterdiridarikomitmenuntukbelajar, visidanketerbukaan(Nasutionetal, 2011:.. 338setelahSinkulaetal, 1997).

\section{Calantoneetal.}

(2002)mendefinisikanbelajarorientasiseb agaikegiatanorganisasiuntukmenambahk andanmenggunakanpengetahuanuntukm eningkatkansaing.Selanjutnya, orientasipembelajarantercermindalamup ayapeningkatanolehkaryawanuntuksecar aaktifmemperluasataurepertoaryang adateknisdanketerampilansosial, sehinggabelajarcaracarabarudanlebihbaikdariinteraksidenga npelanggan.

\subsection{Hipotesis}

2.2.1 $\mathrm{H}_{1}=$ Orientasi Pelanggan berpengaruh secara positif terhadap Penjualan Adaptif PT. Oriflame. 
2.2.2 $\mathrm{H}_{2}=$ Orientasi Pembelajaran tidak berpengaruh secara signifikan terhadap Penjualan Adaptif PT. Oriflame.

2.2.3 $\mathrm{H}_{3}=$ Motivasi Intrinsik tidak berpengaruh secara signifikan terhadap Penjualan Adaptif PT. Oriflame.

\section{METODOLOGI PENELITIAN}

\subsection{Sifat}

Penelitian ini adalah penelitian deskriptif korelatif. PenelitianDeskriptif korelatif bertujuan untuk mendeskripsikan peristiwa yang terjadi pada saat ini dandifokuskan untuk mengkaji adanya hubungan faktor tanpa adanya suatu perlakuan dari peneliti.

3.2 Metode pengumpulan data

Dalam penelitian ini, metode pengumpulan data yang dilakukan adalah dengan menggunakan angket atau kuesioner yang merupakan suatu pengumpulan data dengan memberikan atau menyebarkan daftar pertanyaan kepada responden dengan harapan memberikan respon atas daftar pertanyaan tersebut (Hussein Umar, 1999). Teknik ini dilakukan untuk mengumpulkan data primer.

3.3 Sampel

Dalam penelitian ini yang menjadi populasi penelitian adalah tenaga penjual pada PT Oriflame Indonesia cabang Yogyakarta yang berjumlah 50 orang. Metode pengambilan sampel yang akan digunakan dalam penelitian ini adalah metode sensus yang memakai semua anggota populasi sebagai sampel dalam penelitian. Jadi jumlah responden pada penelitian ini adalah 50 orang.

\subsection{Definsi Operasional}

\subsubsection{Orientasi Pelanggan}

(Brown, dkk., 2002) mendefinisikan Orientasi pelanggan adalah sebagai tendensi atau kecenderungan karyawan dalam memenuhi kebutuhan pelanggan dalam konteks kerja (Brown, dkk., 2002). Variabel tersebut dapat diketahui dengan kuesioner dan mengukus jawaban dengan skala ordinal.

\subsubsection{Orientasi Pembelajaran}

Calantone et al. (2002) mendefinisikan orientasi pembelajaran sebagai kegiatan organisasi untuk menambahkan dan menggunakan pengetahuan untuk meningkatkan saing. Variabel tersebut dapat diketahui dengan kuesioner dan mengukus jawaban dengan skala ordinal.

\subsubsection{Motivasi Intrinsik}

Motivasi intrinsik adalah keinginan bertindak yang disebabkan faktor pendorong dari dalam diri (internal) individu. Individu yang digerakkan oleh motivasi intrinsik, baru akan puas kalau kegiatan yang dilakukan telah mencapai hasil yang terlibat dalam kegiatan itu (Thornburgh dalam Elida Prayitno, 1989:10). Variabel tersebut dapat diketahui dengan kuesioner dan mengukus jawaban dengan skala ordinal.

\subsection{Analisis Data}

3.5.1 Uji Validitas

Uji validitas digunakan untuk mengukur sah atau valid tidaknya suatu kuisioner. Suatu kuesioner dikatakan valid jika pertanyaan pada kuisioner mampu untuk mengungkapkan sesuatu yang akan diukur oleh kuisioner tersebut (Ghozali,2006).

\subsubsection{Uji Reliabilitas}

Uji reabilitas merupakan alat untuk mengukur suatu kuesioner yang merupakan 
indikator dari variabel atau

konstruk. Pengujian reabilitas

dilakukan menggunakan bantuan

progam SPSS, dengan cara menghitung item total correlation masing-masing indikator dan koefisien Cronbach's Alpha dari masingmsing indikator. Aturan umum yang dipakai Cronbach's Alpha

- 0.60 sudah mencerminkan yang reliabel (Ghozali,2006).

3.5.3 Metode Regresi Linear Berganda

Analisis ini digunakan untuk mengetahui seberapa besar pengaruh variabel bebas yaitu : orientasi pelanggan (X1), orientasi pembelajaran (X2), dan motivasi intrinsik (X3) terhadap variabel terikatnya yaitu penjualan adaptif (Y). Persamaan regresi linier berganda adalah sebagai berikut (Ghozali, 2006).

\subsubsection{Uji Hipotesi}

\subsubsection{Uji F}

$\begin{array}{lr}\text { Uji F digunakan } \\ \text { pada } & \text { dasarnya } \\ \text { menunjukkan } & \text { apakah } \\ \text { semua } & \text { variabel }\end{array}$ independen atau bebas yang dimasukkan dalam model mempunyai pengaruh secara bersama-sama terhadap variabel dependen atau terikat (Ghozali, 2006).

1. Jika F hitung - F table, maka hipotesa yang menyatakan ada pengaruh yang signifikan antara orientasi pelanggan (X1), orientasi pembelajaran (X2), motivasi intrinsik (X3), terhadap penjualan adaptif (Y) adalah diterima.

2. Jika $\mathrm{F}$ hitung - $\mathrm{F}$ table, maka hipotesa yang menyatakan ada pengaruh yang signifikan antara orientasi pelanggan (X1), orientasi pembelajaran (X2), motivasi intrinsik (X3), terhadap penjualan adaptif (Y) adalah ditolak.

\subsubsection{Uji t}

Pengujian ini digunakan untuk menentukan apakah dua sampel tidak berhubungan, memiliki rata-rata yang berbeda. Uji t dilakukan dengan cara membandingkan perbedaan antara dua nilai rata-rata dengan standar error dari perbedaan rata-rata dua sampel (Ghozali, 2006)

1. Jika $\mathrm{t}$ hitung - $\mathrm{t}$ tabel, maka hipotesa yang menyatakan ada pengaruh yang positif dan signifikan antara orientasi pelanggan (X1), orientasi pembelajaran (X2), motivasi intrinsik (X3), terhadap penjualan adaptif (Y) adalah diterima.

2. Jika $\mathrm{t}$ hitung $\cdot \mathrm{t}$ table, maka hipotesa yang menyatakan ada pengaruh yang positif dan signifikan antara orientasi pelanggan (X1), orientasi pembelajaran (X2), motivasi intrinsik 
(X3), terhadap penjualan adaptif (Y) ditolak.

\section{HASIL DAN PEMBAHASAN}

\subsection{Uji Validitas}

Uji validitas dianalisis dengan cara membandingkan nilai $\mathrm{r}$ hitung (pada kolom Correlated Item-Total Correlation) dengan $\mathrm{r}$ tabel $(\mathrm{df}=\mathrm{n}-\mathrm{k})$. Jika $\mathrm{r}$ hitung $>\mathrm{r}$ tabel, artinya item pertanyaan berkolerasi signifikan terhadap skor total, maka dinyatakan valid, sedangkan jika $r$ hitung $<$ $r$ tabel, artinya item pertanyaan berkolerasi signifikan terhadap skor total, maka dinyatakan tidak valid.

- Berdasarkantabel di atasdapatdiketahuibahwa6bu tir item

padavariabelOrientasi

Pelanggansemuanya valid. Hal

inidapatkitalihatpadakolomk orelasi item bahwa hasil $r$ hitung $>\mathrm{r}$ tabel,maka dikatakan valid.

- Berdasarkantabel di atasdapatdiketahuibahwa5but ir item padavariabelOrientasi Pembelajaransemuanya valid. Hal inidapatkitalihatpadakolomko relasi item bahwa hasil $r$ hitung $>\mathrm{r}$ tabel,maka dikatakan valid.

- Berdasarkantabel di atasdapatdiketahuibahwa5but ir item pada variable Motivasi Intrinsiksemuanya valid. Hal inidapatkitalihatpadakolomko relasi item bahwa hasil $r$ hitung $>\mathrm{r}$ tabel,maka dikatakan valid.

4.2 Uji Reliabilitas

Hasilujireliabilitas X1 ( Orientasi Pelanggan) menunjukannilaicronbach's alphasebesar 0,733

Nilai

0,733adalahnilai yang

baikkarenakeandalankisaran 0,60 bisaditerima. Hasilujireliabilitas X2( Orientasi

Pembelajaran)menunjukannilaicronbach 's alphasebesar $0,738 \quad$ Nilai 0,738adalahnilai yang baikkarenakeandalankisaran $\quad 0,60$ bisaditerima. Hasilujireliabilitas X3( Motivasi Intrinsik )menunjukannilaicronbach's

alphasebesar $\quad 0,693 \quad$ Nilai 0,693adalahnilai yang baikkarenakeandalankisaran $\quad 0,60$ bisaditerima.HasilujireliabilitasY

Penjualan Adaptif) menunjukannilaicronbach's

alphasebesar $\quad 0,763 \quad$ Nilai 0,763adalahnilai yang baikkarenakeandalankisaran $\quad 0,60$ bisaditerima.

\subsection{Regresi Linear Berganda}

Nilai Beta yang berarti bahwa variabel X1 (Orientasi Pelanggan) mempengaruhi $\mathrm{Y}$ (Penjualan Adaptif) dengan koefisien sebesar 0,284 dengan tingkat signifikansi $0,048<0,05$ yang artinya variabel Orientasi Pelanggan berpengaruh terhadap penjualan adaptif. Sedangkanvariabel $\mathrm{X} 2 \quad$ ( Orientasi Pembelajaran) tidak mempengaruhi $\mathrm{Y}$ ( Penjualan Adaptif ) dengan koefisien sebesar 0,187dengantingkatsignifikansi $\quad 0,191>0,05$ yang artinyavariabelOrientasi Pembelajarantidak

berpengaruhterhadapPenjualan Adaptif. Dan variabel X3 ( Motivasi Intrinsik) tidak mempengaruhi Y ( Penjualan Adaptif ) dengan koefisien sebesar 0,052 dengan tingkat signifikansi $0,709>0,05$ yang artinya variabel Motivasi Intrinsik tidak berpengaruh terhadap penjualan adaptif.Dengandemikian, dapatkitaperolehhasilpersamaanregresiyaitu $\mathrm{Y}=$ $0,284 \mathrm{X} 1+0,187 \mathrm{X} 2+0,052 \mathrm{X} 3$.

4.4 Uji Hipotesis

\subsubsection{Uji F}

Berdasarkan pengujian statistik dengan metode uji simultan atau uji $\mathrm{F}$, dimana tingkat signifikan yang diperoleh lebih besar yakni sebesar 0,063 dari standar signifikan yakni $5 \%$ atau 0,05 dan perbandingan antara $\mathrm{F}$ hitung dan $\mathrm{F}$ tabel, di mana $\mathrm{F}$ hitung sebesar 2,600 lebih kecil dari $\mathrm{F}$ 
tabel yakni 2,807, maka dapat simpulkan bahwa Ha diterima artinya variabel independen tidak berpengaruh terhadap penjualan adaptif.

\subsubsection{Uji t}

- signifikansi sebesar 0,048 atau 4,8\%. Jadi dapat dikatakan bahwa tingkat signifikansi variabel Orientasi pelanggan berada dibawah standar, artinya variabel ini memiliki pengaruh positif dan signifikan terhadap penjualan adaptif.

- signifikasi sebesar 0,191 atau 19,1\%. Jadi dapat dikatakan bahwa tingkat signifikansi variabel Orientasi pembelajaran berada diatas standar, artinya variabel ini tidak berpengaruh terhadap penjualan adaptif.

- signifikansi sebesar 0,709 atau 7,09\%. Jadi dapat dikatakan bahwa tingkat signifikansi variabel Motivasi intrinsik berada diatas standar, artinya variabel ini tidak berpengaruh terhadap penjualan adaptif.

4.5 Uji Koefisien Determinasi $\left(\mathrm{R}^{2}\right)$

Dalam hal ini dapat diartikan bahwa penjualan adaptif mampu dijelaskan oleh variabel orientasi pelanggan,orientasi pembelajaran dan motivasi intrinsik dengan nilai sebesar $8,9 \%$, sedangkan sisanya sebesar $91,1 \%$ (100\%-8,9\%) dijelaskan oleh variabel lain yang tidak diteliti dalam penelitian ini.

\subsection{Pembahasan}

Dalam hal ini dapat diartikan bahwa penjualan adaptif mampu dijelaskan oleh variabel orientasi pelanggan,orientasi pembelajaran dan motivasi intrinsik dengan nilai sebesar $8,9 \%$, sedangkan sisanya sebesar $91,1 \%$ (100\%-8,9\%) dijelaskan oleh variabel lain yang tidak diteliti dalam penelitian ini.
Dari hasil regresi berganda dalam bentuk persamaan yaitu $\mathrm{Y}=$ $0,284 \mathrm{X} 1+0,187 \mathrm{X} 2+0,052 \mathrm{X} 3$ dapat dilihat diantara 3 variabel Oreintasi Pelanggan, Orientasi Pembelajaran dan Motivasi Intrinsik hanya variabel Orientasi Pelanggan saja berpengaruh terhadap Penjualan Adaptif artinya pelayanan yang diberikan sesuai dengan kebutuhan pelanggan. Oriflame telah dikenal dibanyak tempat di dunia dan terjadi karena loyalitas para konsultan dan harapan dari para pelanggan.Konsultan dan karyawan Oriflame akan membuat Oriflame berbeda dengan perusahaan direct selling lainnya. Hubungan langsung antara produsen dan konsumen telah merubah pola berbelanja kita, sudah tentu ini akan membawa manfaat bagi kita semua tidak hanya nilai uang terhadap kualitas produk tetapi juga pada pelayanan dan kenyamanan yang ditawarkan oleh sistem penjualan ini.

Hasil uji hipotesis 1 menunjukkan signifikansi sebesar 0,048 atau $4,8 \%$. Jadi dapat dikatakan bahwa tingkat signifikansi variabel Orientasi pelanggan berada dibawah standar, artinya variabel ini memiliki pengaruh positif dan signifikan terhadap penjualan adaptif.

Hasil uji hipotesis 2 menunjukkan signifikasi sebesar 0,191 atau $19,1 \%$. Jadi dapat dikatakan bahwa tingkat signifikansi variabel Orientasi pembelajaran berada diatas standar, artinya variabel ini tidak berpengaruh terhadap penjualan adaptif.

Hasil uji hipotesis 3 menunjukkan signifikansi sebesar 0,709 atau $7,09 \%$. Jadi dapat dikatakan bahwa tingkat signifikansi variabel Motivasi intrinsik berada diatas standar, artinya variabel ini tidak berpengaruh terhadap penjualan adaptif. 


\section{KESIMPULAN}

5.1 Hasil uji hipotesis 1 menunjukkan signifikansi sebesar 0,048 atau 4,8\%. Jadi dapat dikatakan bahwa tingkat signifikansi variabel Orientasi pelanggan berada dibawah standar, artinya variabel ini memiliki pengaruh positif dan signifikan terhadap penjualan adaptif.

5.2 Hasil uji hipotesis 2 menunjukkan signifikasi sebesar 0,191 atau $19,1 \%$. Jadi dapat dikatakan bahwa tingkat signifikansi variabel Orientasi pembelajaran berada diatas standar, artinya variabel ini tidak berpengaruh terhadap penjualan adaptif.

5.3Hasil uji hipotesis 3 menunjukkan signifikansi sebesar 0,709 atau 7,09\%. Jadi dapat dikatakan bahwa tingkat signifikansi variabel Motivasi intrinsik berada diatas standar, artinya variabel ini tidak berpengaruh terhadap penjualan adaptif.

\section{REFERENSI}

.Weitz, Barton A., Harish Sujan, and Mita Sujan (1986), "Knowledge, Motivation, and Adaptive Behavior: A Framework for Improving Selling Effectiveness," Journal of Marketing,50 (October), 174191.

Jaramillo, Fernando, William B. Locander, Paul E. Spector, and Eric G. Harris (2007), "Getting the Job Done: The Moderating Role of Initiative on the Relationship Between Intrinsic Motivation and Adaptive Selling," Journal of Personal Selling \& Sales Management,27, 1 (Winter), 59-74.

Sujan, Harish (1986), "Smarter Versus Harder: An Exploratory Attributional Analysis of Salespeople's Motivation," Journal of Marketing Research,23 (February), 41-49.

Pelham, A. (2002a). An exploratory model and initial test of the influence of firm level consulting-oriented sales force programs on sales force performance.Journal of Personal Selling and Sales Management,22(2), 97-109.

Spiro, R., \& Weitz, B. (1990). Adaptive selling: Conceptualization, measurement, and validity.Journal of Marketing

Research,27(February), 61-69.

Pelham, A., \& Wilson, D.T. (1996). A longitudinal study of the impact of market structure, firm structure, strategy, and market orientation culture on dimensions of small firm performance.Journal of the Academy of Marketing Science,24 (1), 27-43

Weitz, B.A. (1978). The relationship between salesperson performance and understanding of customer decision making.Journal of Marketing Research,15 (November), 501-516.

Spiro, Rosann L., and Barton A. Weitz (1990), "Adaptive Selling:

Conceptualization, Measurement, and Nomological Validity," Journal of Marketing Research, 27 (February), 61-69.

Sujan Harish, Barton A. Weitz, and Nirmalya Kumar (1994),

"Learning Orientation, Working Smart, and Effective Selling,"Journal of Marketing,58 (3), 39-52.

Pelham, A. (2006). Sales force training: What is needed versus what is happening.Journal ofSelling and Major Account Management, 6(5), 3-12

Junwu Chai (Ph.D., Xi'an Jiaotong University), Associate Professor

of Marketing, School of Management and Economics, University

of Electronic Science and Technology of China, Chengdu, Sichuan,

China. 
JURNAL MANAJEMEN VOL 4 NO.2 DESEMBER 2014 